\title{
ИЗМЕНЧИВОСТЬ СОСТАВА БИТУМОИДОВ ПО РАЗРЕЗУ (ГОРЮЧИЕ СЛАНЦЫ ТОДИНСКОЙ ПЛОЩАДИ УЗБЕКСКОЙ ССР)
}

\author{
(Представил О. Эйзен)
}

Результаты исследований в Институте химии АН ӘССР состава битумоидов нижнеэоценовых горючих сланцев Средней Азии опубликованы в $\left[{ }^{1-5}\right]$. В настоящей работе изучали сланец Тодинской площади, залегающий в области эпиплатформенного орогена, т. е. занимающий промежуточное положение между сузакскими сланцами Западного Узбекистана $[2,4]$, приуроченными к тектонически относительно спокойному региону, и сланцами Таджикской $\mathrm{CCP}[1,3,5]$, залегающими в активной по термобарическим воздействиям зоне - орогене Тянь-Шаня. По сравнению с горючими сланцами расположенного вблизи Байсунского месторождения, сланцы Тодинской площади, являющиеся аналогом первых, залегают более глубоко и, по-видимому, менее затронуты гипергенными процессами. В отличие от сланцев площади Капали [4], тодинский сланец сформировался в более глубоководной части бассейна.

Образцы сланца были отобраны из скважины 7-р Тодинской гидрогеологической партией Министерства геологии Узбекской ССР в северозападной части Сурхандарьинской впадины юго-западнее пос. Байсун. Пласт сланца вскрыт в интервале $294,5-296$ м. Известняки бухарских слоев покрывают верхнепалеоценовые аргиллиты мощностью 27,5 м, на них (в подошве нижнего эоцена) залегает полутораметровый пласт сланца, перекрытый аргиллитами сузакских слоев мощностью 12 м. На последних с размывом и угловым несогласием лежат буроцветы неогена мощностью 282 м. Пробы сланца (обр. 1-5) отобраны снизу вверх по разрезу.

Битумоиды извлекали из предварительно измельченного сланца экстракцией последовательно смесью бензола и метилового спирта (3:1 по объему) и диэтиловым эфиром; в последующем экстракты объединяли. Омыляемые соединения выделяли из битумоида 0,5 M раствором гидроокиси калия; для газохроматографического анализа их метилировали диазометаном. Оставшуюся часть битумоида разделяли на групповые компоненты методом тонкослойной хроматографии на силикагеле Л (ЧССР) с использованием $H$-гексана в качестве элюента; нейтральные гетероатомные соединения разделяли вторично на нейтральной окиси алюминия (по Брокману II, ВНР), элюент - бензол. Выделенные из битумоидов группы соединений анализировали газохроматографически на аппарате «Хром-4» с применением колонок различной полярности, инфракрасные спектры снимали на приборе UR-10.

Характеристика исходных образцов сланцев приведена в табл. 1, данные о выходе и составе битумоидов представлены в табл. 2.

Если выход битумонда в расчете на органическое вещество (ОВ) в пределах рассматриваемого разреза относительно постоянен (и значи- 
Таблица 1

Характеристика исходных образцов сланцев, вес. \%

\begin{tabular}{|c|c|c|c|c|c|}
\hline \multirow{2}{*}{ Показатель } & \multicolumn{5}{|c|}{ Номер образца } \\
\hline & 1 & 2 & 3 & 4 & 5 \\
\hline $\begin{array}{l}\text { Влага аналитическая } W^{a} \\
\text { Зола } A^{\circ} \\
\text { Углекислота карбонатов }\left(\mathrm{CO}_{2}\right)^{\mathrm{c}} \text { карб }\end{array}$ & $\begin{array}{r}2,4 \\
63,5 \\
7,1\end{array}$ & $\begin{array}{r}1,5 \\
55,8 \\
9,9\end{array}$ & $\begin{array}{r}2,9 \\
73,1 \\
4,4\end{array}$ & $\begin{array}{r}3,3 \\
81,5 \\
2,2\end{array}$ & $\begin{array}{r}2,3 \\
67,1 \\
4,1\end{array}$ \\
\hline $\begin{array}{l}{\left[100-\mathrm{Ac}^{\mathrm{c}}-\left(\mathrm{CO}_{2}\right)^{\mathrm{c}} \text { кар } 6\right]} \\
\mathrm{Cepa} \mathrm{общая} \\
\mathrm{K}_{2} \mathrm{O} \\
\mathrm{P}_{2} \mathrm{O}_{5} \\
\mathrm{~V}_{2} \mathrm{O}_{5} \\
\mathrm{Mo}\end{array}$ & $\begin{array}{c}29,4 \\
4,0 \\
0,27 \\
2,15 \\
0,52 \\
0,13\end{array}$ & $\begin{array}{c}34,3 \\
4,0 \\
1,37 \\
1,80 \\
0,45 \\
0,15\end{array}$ & $\begin{array}{l}22,5 \\
2,1 \\
1,59 \\
0,73 \\
0,26 \\
0,03\end{array}$ & $\begin{array}{l}16,3 \\
1,5 \\
2,56 \\
0,55 \\
0,24 \\
0,02\end{array}$ & $\begin{array}{l}28,8 \\
2,6 \\
1,22 \\
0,72 \\
0,41 \\
0,07\end{array}$ \\
\hline $\begin{array}{l}\text { Элементный состав органического } \\
\text { вещества *: } \\
\text { углерод } \\
\text { водород } \\
\text { азот } \\
\text { кислород+сера (по разности) } \\
\text { Атомное отношение Н/C }\end{array}$ & $\begin{array}{r}63,9 \\
7,3 \\
2,7 \\
26,1 \\
1,37\end{array}$ & $\begin{array}{r}67,2 \\
7,4 \\
2,8 \\
22,6 \\
1,32\end{array}$ & $\begin{array}{r}61,6 \\
8,3 \\
2,8 \\
27,3 \\
1,62\end{array}$ & $\begin{array}{c}52,4 \\
8,1 \\
3,2 \\
36,3 \\
1,85\end{array}$ & $\begin{array}{r}62,7 \\
7,6 \\
2,7 \\
27,0 \\
1,45\end{array}$ \\
\hline
\end{tabular}

* По данным анализа обработанных 10\%-ной соляной кислотой образцов.

Таблица 2

Выход и состав битумоидов, вес. \%

\begin{tabular}{|c|c|c|c|c|c|}
\hline \multirow{2}{*}{ Показатель } & \multicolumn{5}{|c|}{ Номер образца } \\
\hline & 1 & 2 & 3 & 4 & 5 \\
\hline $\begin{array}{l}\text { Выход суммарного битумоида: } \\
\text { на сухой сланец } \\
\text { на органическое вещество } \\
\text { Элементный состав битумоида: } \\
\text { углерод } \\
\text { водород } \\
\text { азот } \\
\text { кислород+сера (по разности) } \\
\text { Атомное отношение Н/C } \\
\text { Групповой химическнй состав биту- } \\
\text { монда: } \\
\text { неароматические углеводороды } \\
\text { одноядерные ароматические угле- } \\
\text { водороды } \\
\text { конденсированные ароматические } \\
\text { углеводороды } \\
\text { нейтральные гетероатомные соеди- } \\
\text { нения } \\
\text { кислотные соединения } \\
\text { из них эфирорастворимые } \\
\text { Элементный состав высокомолекуляр- } \\
\text { ных, не растворимых в эфире кис- } \\
\text { лот: } \\
\text { углерод } \\
\text { водород } \\
\text { азот } \\
\text { кислород+сера (по разности) } \\
\text { Атомное отношение Н/С }\end{array}$ & $\begin{array}{c}2,63 \\
8,95 \\
75,9 \\
9,7 \\
2,4 \\
12,0 \\
1,53 \\
\\
4 \\
2 \\
4 \\
\\
25 \\
65 \\
14\end{array}$ & $\begin{array}{c}3,04 \\
8,86 \\
76,1 \\
9,2 \\
2,5 \\
12,2 \\
1,45 \\
\\
5 \\
1 \\
5 \\
\\
25 \\
64 \\
13\end{array}$ & $\begin{array}{c}1,99 \\
8,84 \\
75,6 \\
9,4 \\
2,5 \\
12,5 \\
1,49\end{array}$ & $\begin{array}{r}1,38 \\
8,47 \\
69,9 \\
9,0 \\
2,7 \\
18,4 \\
1,55\end{array}$ & $\begin{array}{c}2,53 \\
8,78 \\
75,2 \\
9,5 \\
2,6 \\
12,7 \\
1,52\end{array}$ \\
\hline
\end{tabular}




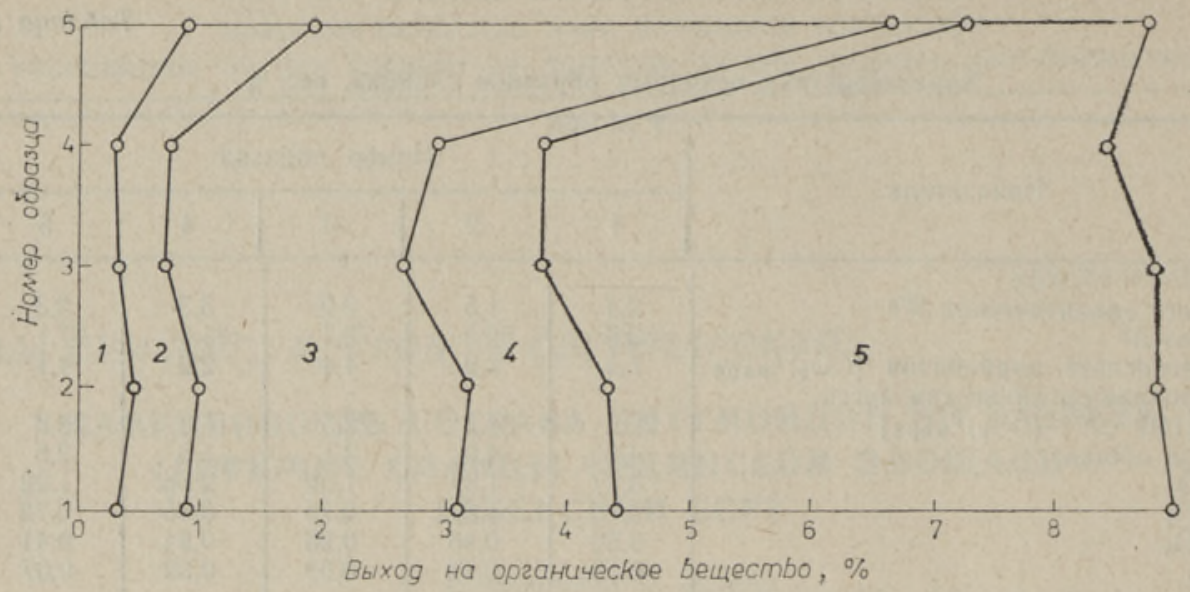

Рис. 1. Изменение выхода и состава битумонда по разрезу: 1 - неароматические углеводороды, 2 - ароматические углеводороды, 3 - нейтральные гетероатомные соединения, 4 - эфирорастворимые кислоты, 5 - высокомолекулярные кислоты.

тельно ниже, чем в западной части бассейна $\left.\left[{ }^{2}\right]\right)$, то его групповой состав меняется существенно (рис. 1).

Газохроматографический анализ показал, что, как и в сланце площади Капали $\left.{ }^{4}\right]$, в тодинском также наблюдается определенная корреляция между составом н-алканов битумоида и содержанием ОВ в породе: чем выше концентрация ОВ, тем больше низших $\boldsymbol{H}$-алканов $\left(\mathrm{C}_{10}-\mathrm{C}_{17}\right)$.

В исследовавшихся экстрактах наряду с алифатическими изопреноидными углеводородами (УВ) содержатся также циклические изопреноиды, в частности стераны $\mathrm{C}_{27}-\mathrm{C}_{29}$.

Несмотря на невысокое содержание в битумоидах ароматических УВ (табл. 2), в инфракрасных спектрах суммарных экстрактов наблюдается интенсивная (особенно в обр. 3-5) полоса поглощения в области $750-780 \mathrm{~cm}^{-1}$. На хроматограммах тонкослойных фракций битумоидов, по адсорбционным свойствам соответствующих одноядерным ароматическим УВ, обнаруживается гомологический ряд соединений, совпадающий с рядом $H$-алкилпроизводных бензола $\mathrm{C}_{11}-\mathrm{C}_{23}$, более ярко выраженный также в обр. 3-5. Основную массу конденсированных ароматических УВ битумоидов составляют замещенные трехъядерные и более сложные соединения. В низкокипящей части соответствующих фракций битумоидов идентифицированы нафталин, его метил-, этил- и диметилпроизводные, аценафтен, флуорен, фенантрен, антрацен, т. е. соединения, свойственные прежде всего продуктам термолиза, а не биогенному материалу.

Нерастворимые в эфире кислоты, составляющие, кроме обр. 5, преобладающую часть битумоидов, характеризуются низким содержанием водорода и высоким - гетероатомов. Расчет по данным табл. 2 показывает, что лишенные высокомолекулярных кислот битумоиды содержат $11,6-12,9 \%$ Н и только $0,7-1,3 \% \mathrm{~N}$, атомное отношение $\mathrm{H} / \mathrm{C}$ составляет в них около 2. Интересно, что в инфракрасных спектрах указанных кислот отсутствует полоса поглощения $750-780 \mathrm{~cm}^{-1}$, характерная для суммарных битумоидов; усиление поглощения в области $1700-1720 \mathrm{~cm}^{-1}$ закономерно (СО-группы карбоксилов).

В эфирорастворимых кислотах наряду с насыщенными монокарбоновыми кислотами нормального строения содержится также немного насыщенных дикарбоновых кислот $\mathrm{C}_{4}-\mathrm{C}_{12}$; из непредельных кислот во всех образцах идентифицирована олеиновая. 


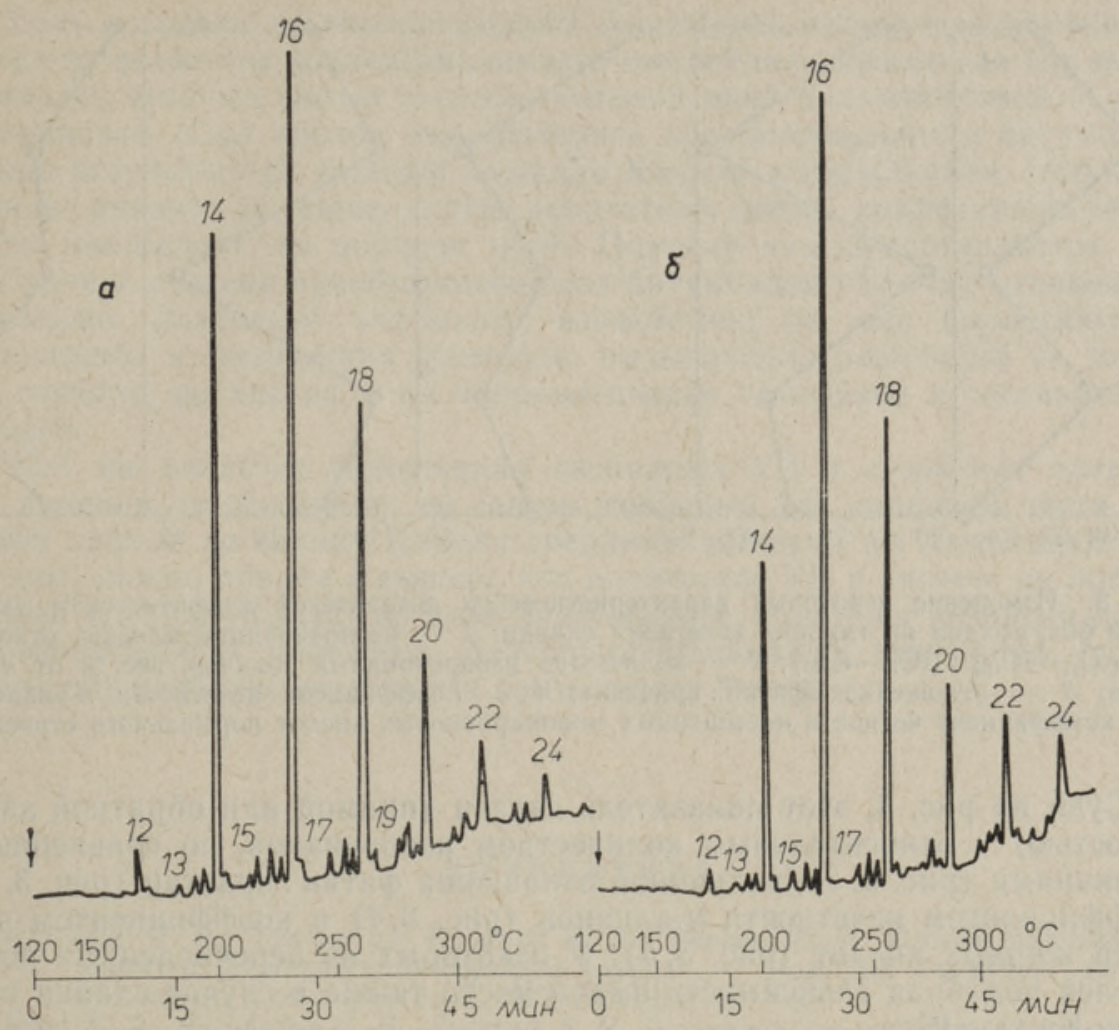

Рис. 2. Хроматограммы малополярных фракций, выделенных из нейтральных гетероатомных соединений битумоидов при их повторном тонкослойном разделении. Образцы $1(a)$ и $5(\sigma)$. Цифры указывают число атомов углерода в молекуле $\boldsymbol{H}$-алкана. Колонка: $8 \%$ апиезона L на хромосорбе $\mathrm{P}, 60-80$ меш, 3,6 м $\times 3$ мм.

В битумоидах установлено также присутствие $н$-алканонов $\mathrm{C}_{9}-\mathrm{C}_{23}$ с карбонильной группой в средней части цепи, однако в целом алифатические кетоны нормального строения играют среди нейтральных кислородных соединений подчиненную роль.

При повторном разделении фракций нейтральных гетероатомных соединений методом тонкослойной хроматографии из них была выделена наименее полярная часть $(7-12 \%$ на фракцию), содержащая н-алканы практически только с четным числом атомов углерода в молекуле (рис. 2). То же отмечалось в случае битумоидов таджикских нижнеэоценовых сланцев $\left[{ }^{3,5}\right]$ и новодмитровского сланца УССР [6]. Предполагалось, что термически нестабильные гетероатомные соединения могут быть источником «четных» парафинов также в некоторых редких нефтях, характеризующихся их преобладанием.

Из графиков изменения некоторых характеристик состава битумоидов (рис. 3) явствует, что между отдельными слоями тодинского сланца эти показатели варьируют даже сильнее, чем средние данные по различным, далеко отстоящим друг от друга площадям распространения сузакских сланцев (табл. 3).

Из перечисленных в табл. 3 показателей одним из наименее зависимых от состава исходного материала и вследствие этого лучше других характеризующих степень преобразованности битумоидов можно считать отношение концентрации деградированных, низших изопренанов (до $i \mathrm{C}_{18}$ включительно) к суммарной концентрации пристана $\left(i \mathrm{C}_{19}\right)$ и фитана $\left(i_{20}\right)$, свойственных малоизмененному биоматериалу.

$4^{*}$

51 


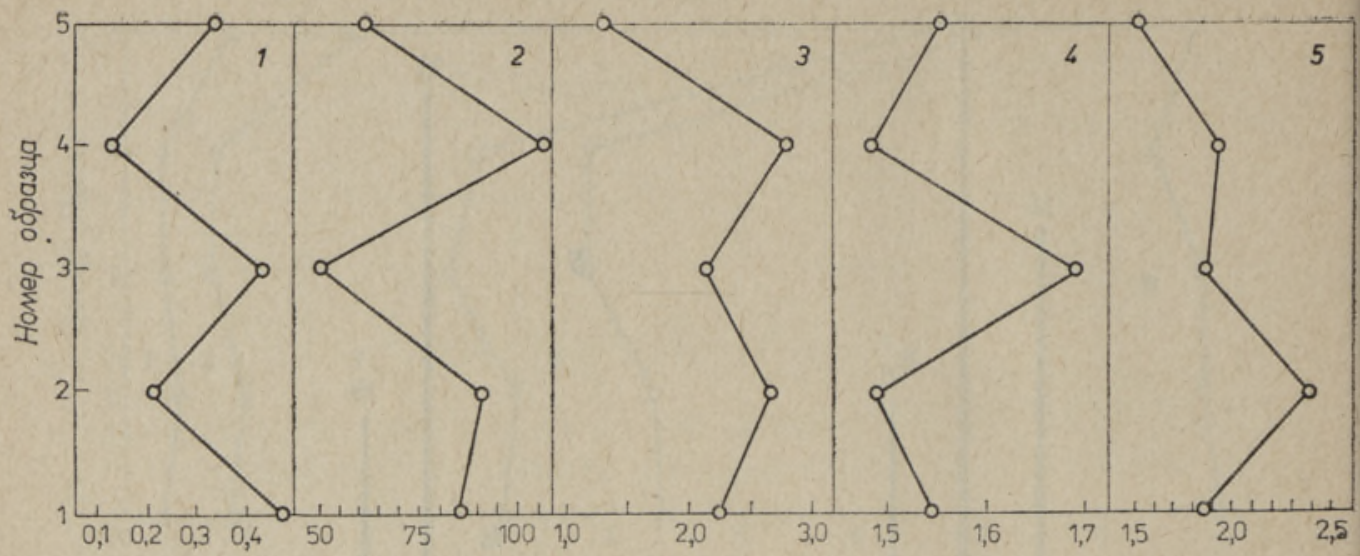

Рис. 3. Изменение некоторых характеристических показателей алифатических соединений битумоидов по глубине залегания сланца: 1 - изопренондные алканы, отношение $\left(i \mathrm{C}_{11}-i \mathrm{C}_{18}\right):\left(i \mathrm{C}_{19}-i \mathrm{C}_{20}\right) ; 2-$ количество изопреноидных алканов, вес. \% от $\boldsymbol{H}$-алканов; 3 - отношение «фитан: пристан»; 4 - коэффициент нечетности $\boldsymbol{H}$-алканов; 5 - коэффнциент четности насыщенных монокарбоновых кислот нормального строения

Судя по рис. 3 , этот показатель связан (прямой или обратной зависимостью) с относительным количеством изопренанов, по сравнению с H-алканами (рис. 3,2 ), величиной отношения фитан : пристан (рис, 3,3 ), коэффициентом нечетности н-алканов (рис. 3,4 ) и коэффициентом четности жирных кислот (рис. 3,5$)$. У некоторых из перечисленных показателей подобная зависимость имела место также в случае сланца площади Капали [4].

таблица 3

Сравнительная характеристика углеводородов и жирных кислот битумоидов сузакских сланцев

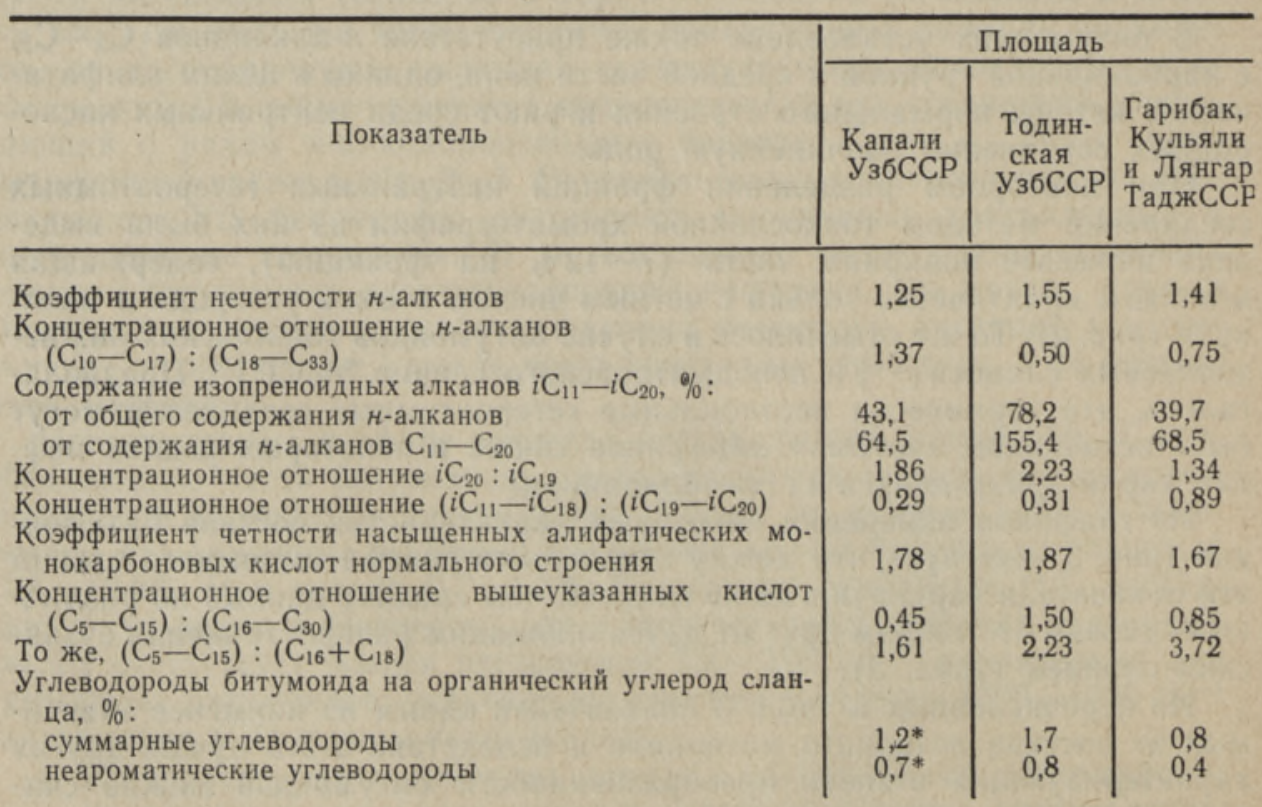

* В среднем по площадям Восточный Чандыр, Капали, Култак-Зеварды, Памук и Уртабулак 2,5 и $1,5 \%$ соответственно. 
Если исходить из относительного количества легких изопренанов, а также из величины концентрационного отношения низших (до $\mathrm{C}_{15}$ включительно) жирных кислот к сумме концентраций пальмитиновой $\left(\mathrm{C}_{16}\right)$ и стеариновой $\left(\mathrm{C}_{18}\right)$ кислот как критериев преобразованности битумоида, то она возрастает от сланцев площади Капали к таджикским (табл. 3); если же принять за основу другие показатели (напр., коэффициент нечетности $н$-алканов), то порядок иной. Поэтому нам представляется, что при оценке степени преобразованности битумоидов горючих сланцев необходимо раздельно учитывать воздействие на них биологических, химических и физических факторов, вызывающих различные не только по глубине, но иногда и по направленности изменения в составе битумоидов,

Что же касается содержания свободных УВ в сузакских сланцах, то, заменив, по-видимому, не совсем типичные для западной части бассейна данные по сланцу Капали средними данными по нескольким площадям, можно придти к выводу, что количество УВ в расчете на органический углерод убывает по мере приближения к региону развития горнообразовательных процессов, благоприятствовавших эмиграции (улетучиванию) наиболее подвижных компонентов битумоида.

\title{
ЛИТЕРАТ У РА
}

1. Клесмент И. Р., Риккен Ю. Т., Уров К. Э., ЯковеИ Ю. А. Состав органического вещества булгаринского горючего сланца. - Изв. АН ТаджССР. Отд-ние физ.-матем. и геол.-хим. наук, 1977, № 3(65), 58-64.

2. Уров К. Э., Авазматов Х. Б., Листрем А. И. Геохимические особенности нижнеоэценовых горючих сланцев Западного Узбекистана. - В кн.: Накопление и преобразование органического вещества современных и ископаемых осадков. М., $1978,133-140$.

3. Яковец Ю. А., Уров К. Э., Листрем А. И. О составе органического вещества сузакских горючих сланцев Таджикской ССР. - В кн.: Всесоюзное совещание «Геохимия горючих сланцев». Тезисы докладов. Таллин, 1978, 99-101.

4. Уров K., Светозарский E., Высоцкая B. Сузакские горючие сланцы Узбекистана: вертикальные вариации в составе битумондов. - Изв. АН ЭССР. Хим., 1984, 33, № 2, 79-86.

5. Уров К. Э., Сумберг А. И., Гинзбург А. И. Петрографические и химические особенности сузакских горючих сланцев Таджикистана. - Горючие сланцы, 1984 (в печати).

6. Уров К. Э., Листрем А. И. Сравнительная характеристика органического вещества горючего сланца и бурого угля Новодмитровского месторождения УССР. Хим. тверд. топл., 1980, № 1, 94-100.

\author{
Ннститут химии \\ Академии наук Эстонской ССР
Опытно-методическая экспедиция
Министерства геологии \\ Узбекской ССР (Ташкент)
}

Поступнла в редакцию

23/III 1984

Ada SUMBERG, K. UROV, J. SVETOZARSKI

\section{BITUMOIDIDE KOOSTISE MUUTUMISEST PIKI LÄBILOIGET (USBEKI NSV TODINSKI LEIUKOHA POLEVKIVIDE POHJAL)}

Todinski leiukoha alameotseeni pōlevkivide ekstraktide keemiline koostis sōltub ladestussügavusest rohkem kui teiste leiukohtade sama vanusega põlevkivide ekstraktide keskmine koostis. Mäetekketsooni lähenemisel vabade süsivesinike sisaldus põlevkivide orgaanilises aines väheneb. 
Ada SUMBERG, K. UROV, Y. SVETOZARSKY

\section{VARIABILITY IN THE COMPOSITION OF BITUMOIDS ALONG SECTION (ON THE BASIS OF TODINSK OIL SHALES OF UZBEKISTAN)}

It has been shown that the chemical composition of bitumoids of the Lower Eocene Todinsk oil shales of Uzbekistan varies with depth more than the average compositions of bitumoids of different oil shales between themselves. At approaching the orogenic zone, the free hydrocarbon content in the oil shale organic matter decreases. To estimate the degree of transformation of extracts, the biological, chemical and physical factors are recommended to be considered separately as they cause different changes in the composition of the extracts. 